\title{
Conversion of a Gemistocytic Astrocytoma to a Fibrillary Astrocytoma after Temozolomide and Radiation Therapy
}

\author{
Brandon C. Gabel ${ }^{1}$, Mary Goolsby ${ }^{2}$, Lawrence Hansen ${ }^{2}$, Bob Carter ${ }^{3}$, Clark Chen ${ }^{4}$ \\ 1. Department of Neurosurgery, University of California, San Diego 2. Department of Pathology, \\ University of California, San Diego 3. Neurosurgery, University of California, San Diego 4. Department of \\ Surgery, University of California, San Diego
}

$\square$ Corresponding author: Brandon C. Gabel, brandoncgabel@gmail.com Disclosures can be found in Additional Information at the end of the article

\section{Abstract}

In most instances, gemistocytic astrocytoma progresses to anaplastic astrocytoma at the time of recurrence. Here, we report an unusual case where a gemistocytic astrocytoma converted to a more benign fibrillary histology after temozolomide/radiation therapy. We present the case of a 26-year-old woman with a history of fibrillary astrocytoma that was followed over a span of eight years and underwent three craniotomies. The pathology from the first craniotomy revealed a fibrillary astrocytoma. The pathology from the second craniotomy (one year after the first resection) revealed findings consistent with a gemistocytic astrocytoma. The pathology from a third craniotomy (seven years after the second resection) revealed a fibrillary astrocytoma without a significant gemistocytic component. This is the first documented case of a gemistocytic astrocytoma converting to a more benign fibrillary pathology at the time of recurrence. We speculate that the phenomenon is the result of the inherently heterogeneous astrocytic subpopulations that were differentially sensitive to chemo/radiation.

Received 10/05/2014

Review began 10/07/2014

Review ended 10/14/2014

Published 10/16/2014

(c) Copyright 2014

Gabel et al. This is an open access article distributed under the terms of the Creative Commons Attribution License CC-BY 3.0., which permits unrestricted use, distribution, and reproduction in any medium, provided the original author and source are credited.
Categories: Neurology, Neurosurgery, Oncology

Keywords: gemistocytic, fibrillary, astrocytoma, temozolomide, radiation, glioma

\section{Introduction}

It is a commonly accepted truism in oncology that the grade and aggressiveness of a tumor increases at the time of recurrence. As an example of this phenomenon, recurrent gemistocytic astrocytoma nearly always exhibit less differentiated or anaplastic histology [1-2]. We present an interesting case of a gemistocytic astrocytoma that converted to a more benign fibrillary histology at the time of recurrence. This is the first documentation of this phenomenon. We hypothesize that the conversion reflected the ablation of the predominant gemistocytic cells by chemoradiation therapy followed by expansion of therapeutically resistant fibrillary subpopulations.

\section{Case Presentation}

The patient is a 26-year-old woman who initially presented with new-onset headache and blurry vision. Her neurologic examination was non-focal and without papilledema. Laboratory findings were unremarkable. Further work-up with a contrast-enhanced MRI revealed a 7.3 by $4.3 \mathrm{~cm}$ cystic lesion in the left parietal-occipital region (Figure 1). Informed patient consent was obtained for all treatment. 


\section{Cureus}

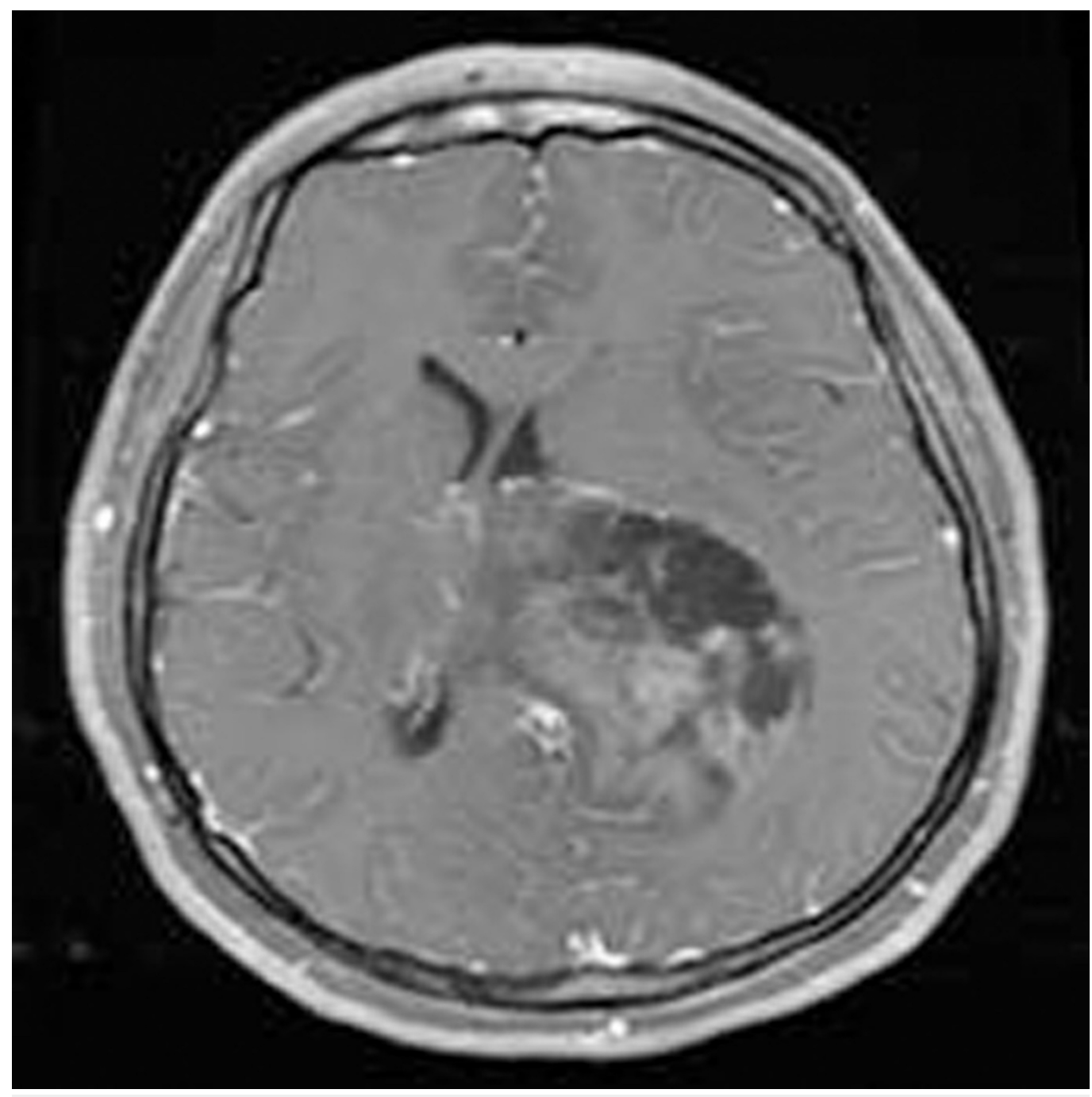

FIGURE 1:

MR imaging and histology related to the first resection. Preoperative T1-weighted MRI with contrast.

The patient underwent a gross-total resection (Figure 2) with pathology demonstrating a Grade II fibrillary astrocytoma (Figure 3). 


\section{Cureus}

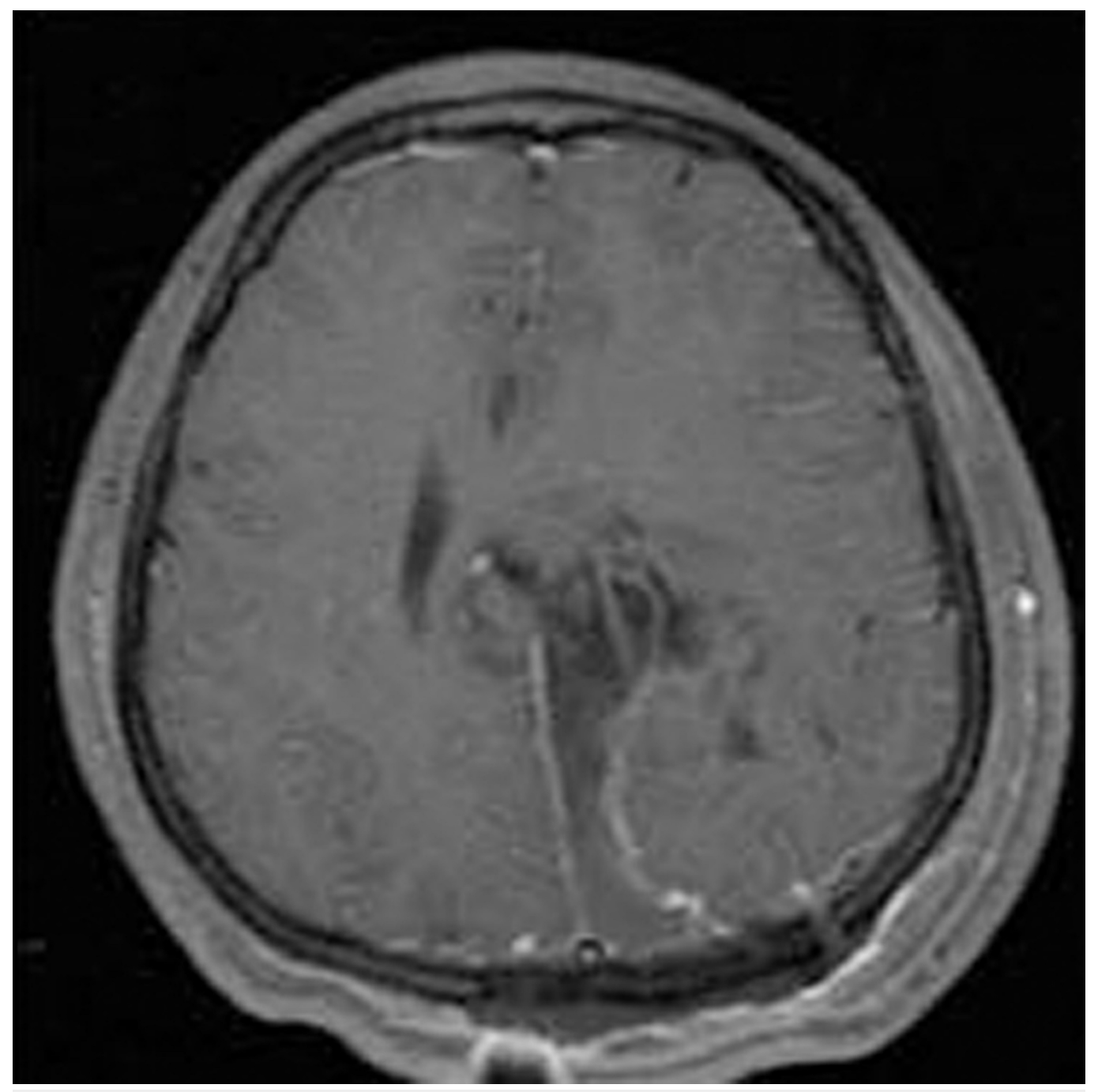

FIGURE 2:

MR imaging and histology related to the first resection. Postoperative T1-weighted MRI with contrast. 


\section{Cureus}

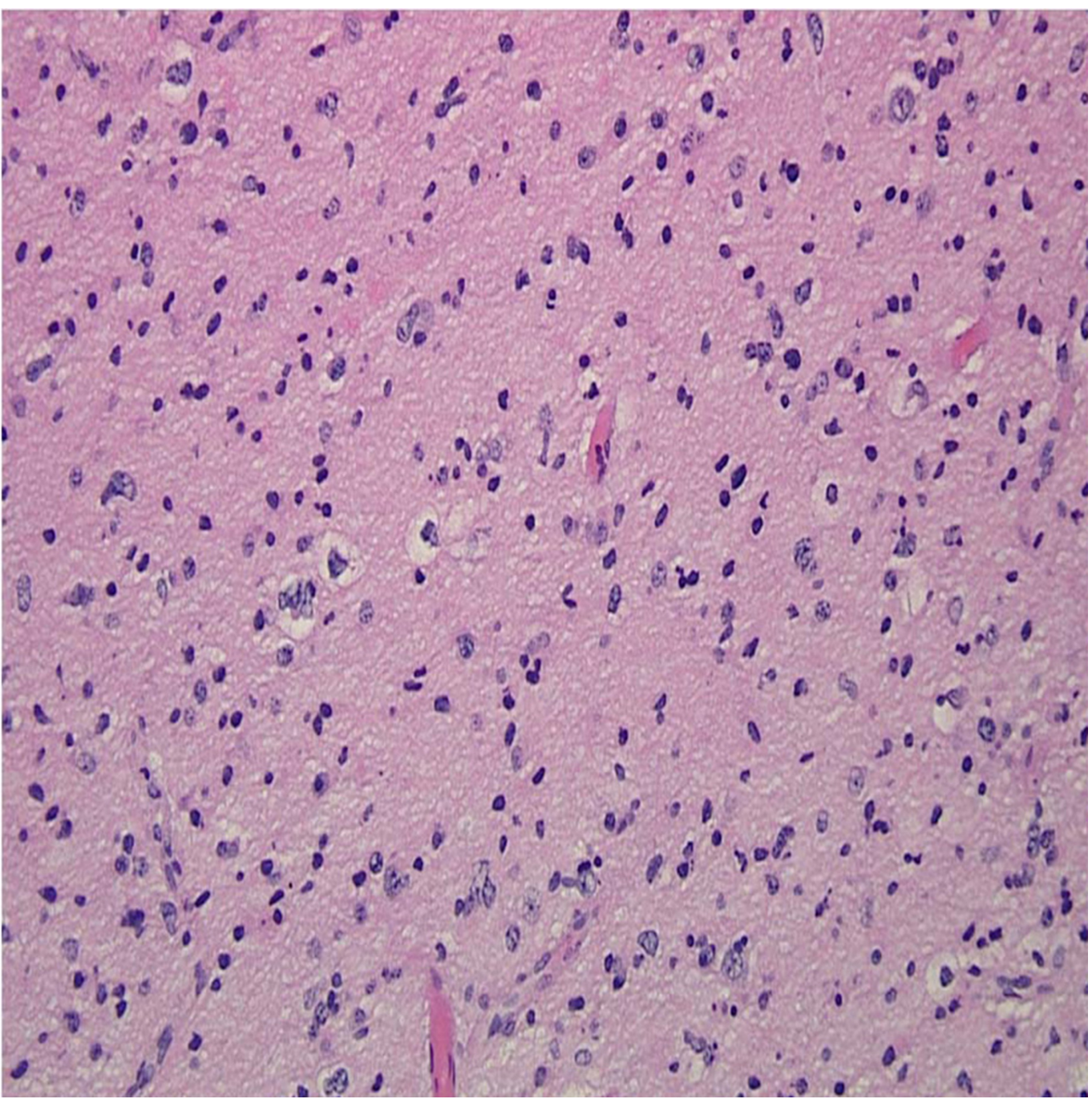

FIGURE 3:

Representative pathology from the resected specimen. Specimen revealed a fibrillary astrocytoma with nuclear pleomorphism and few mitoses, assigned WHO Grade II, fibrillary astrocytoma (hematoxylin-eosin, original magnification x200).

The patient suffered recurrence of her initial symptoms approximately one year after the initial resection. MRI performed at that time revealed tumor in the left posterior frontal and parietal lobes with subsequent spread into and across the corpus (Figure 4). 


\section{Cureus}

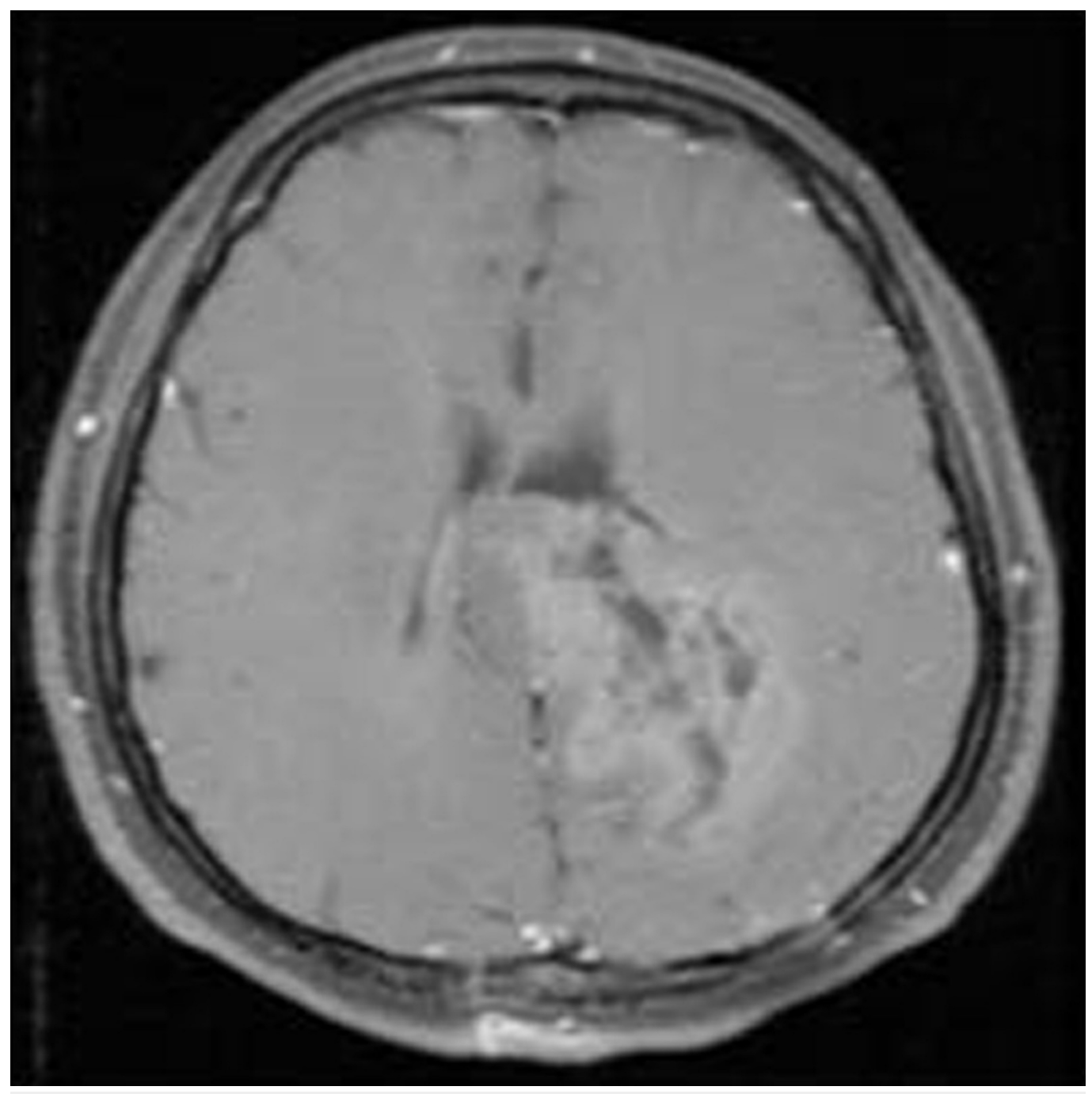

FIGURE 4:

MR imaging and histology related to the second resection. Preoperative T1-weighted MRI with contrast.

The patient underwent a second craniotomy for a subtotal resection (Figure 5). 


\section{Cureus}

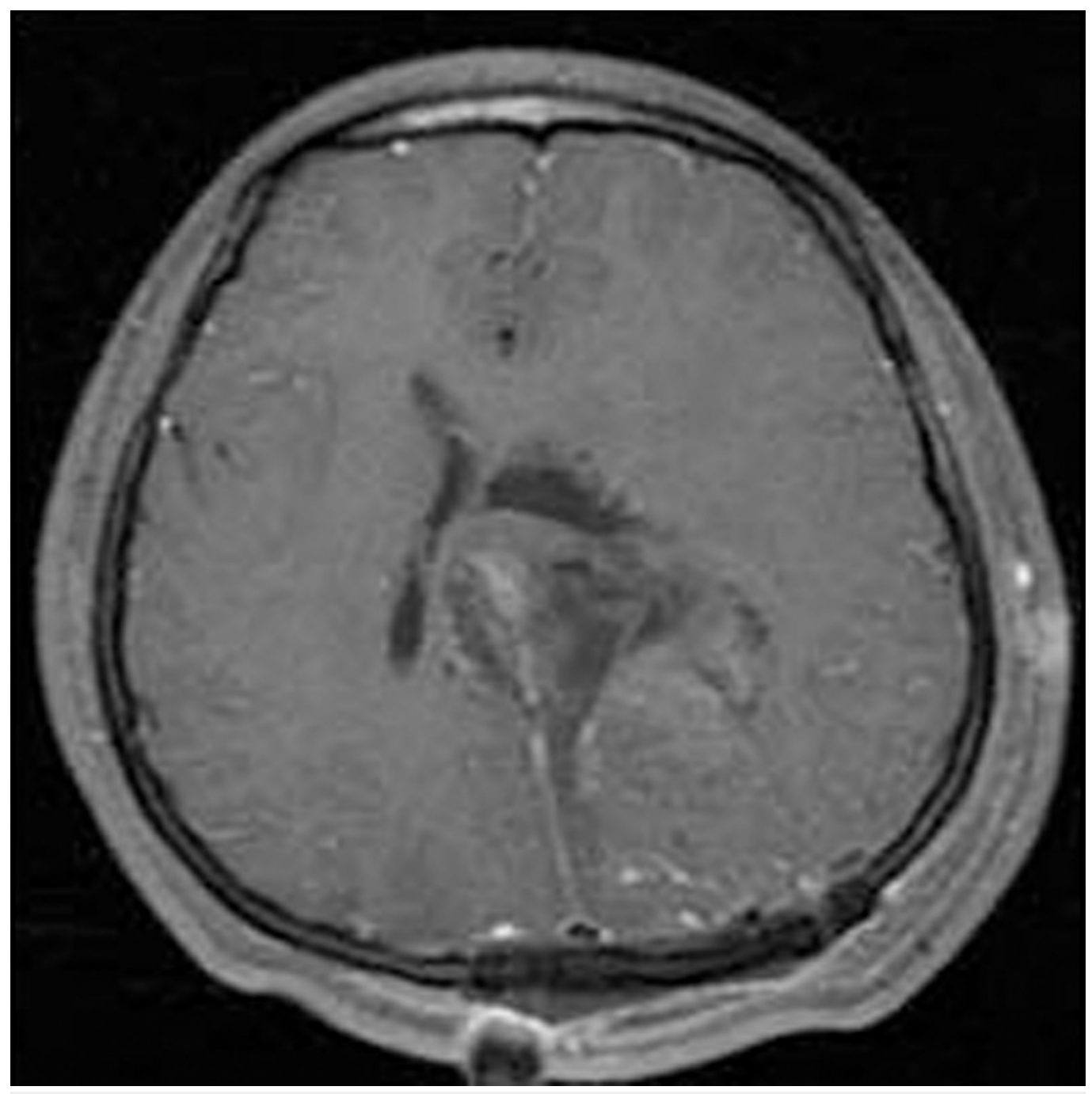

FIGURE 5:

MR imaging and histology related to the second resection. Postoperative T1-weighted MRI with contrast revealed a subtotal resection of the lesion.

Specimens at this time showed pathology consistent with a gemistocytic astrocytoma (Figure ). 


\section{Cureus}

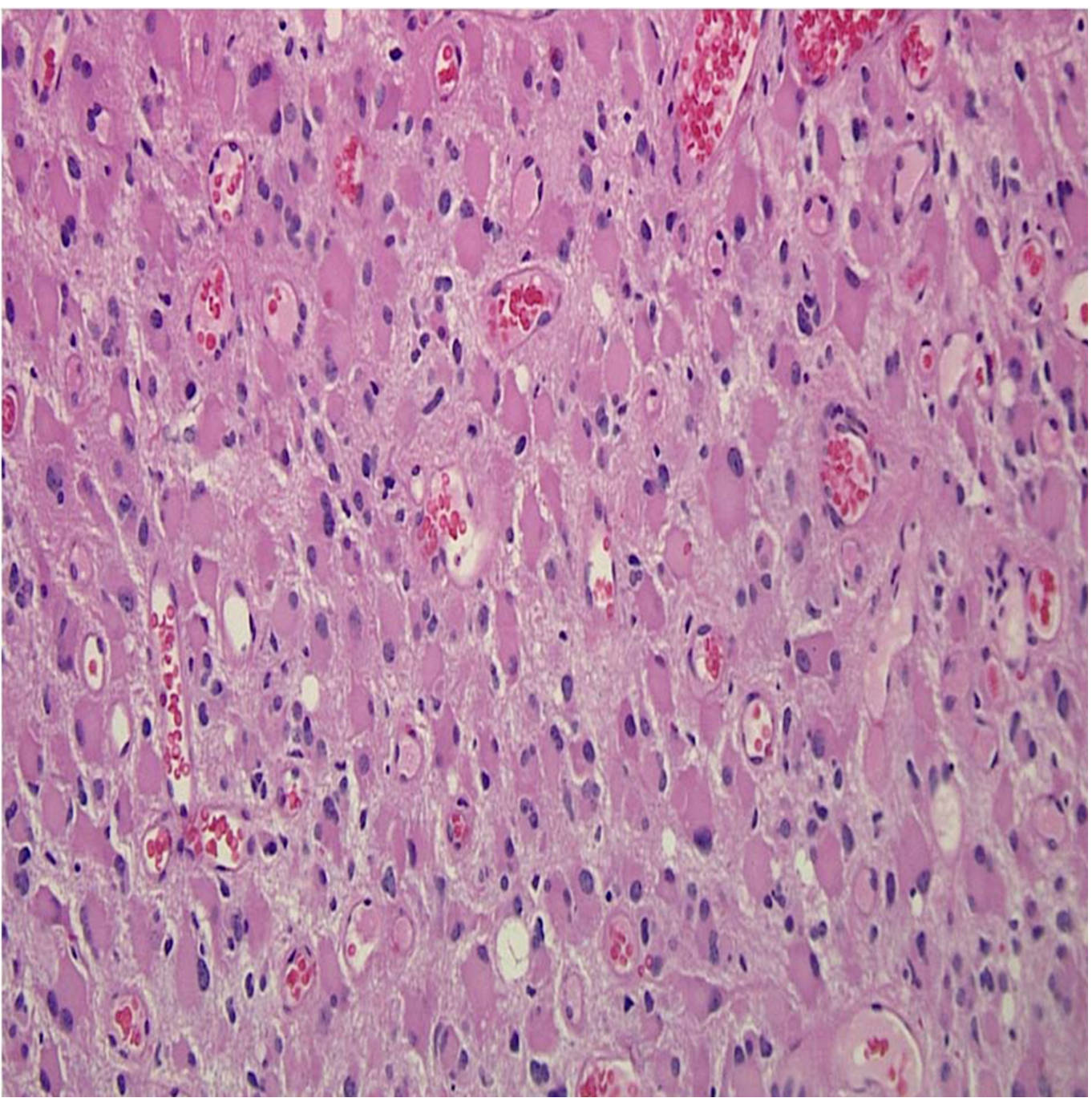

FIGURE 6:

Representative pathology from the resected specimen. Infiltrating astrocytoma dominated by gemistocytes and naked astrocyte nuclei. The tumor was negative for $1 \mathrm{p} / 19 \mathrm{q}$ deletions by FISH. Mitoses were frequent enough to assign WHO Grade III (hematoxylin-eosin, original magnification $\times 200$ ).

Because of the recurrence within a relatively short period and the presence of a more aggressive pathology on recurrence, the patient was treated with concurrent temozolomide and radiation therapy followed by 12 cycles of temozolomide therapy. The patient remained in remission until seven years after the second resection when she again presented with recurrent symptoms. MRI showed interval enlargement of the residual lesion (Figure 7), suggesting a second recurrence. The patient underwent a third craniotomy for tumor resection (Figure 8). 


\section{Cureus}

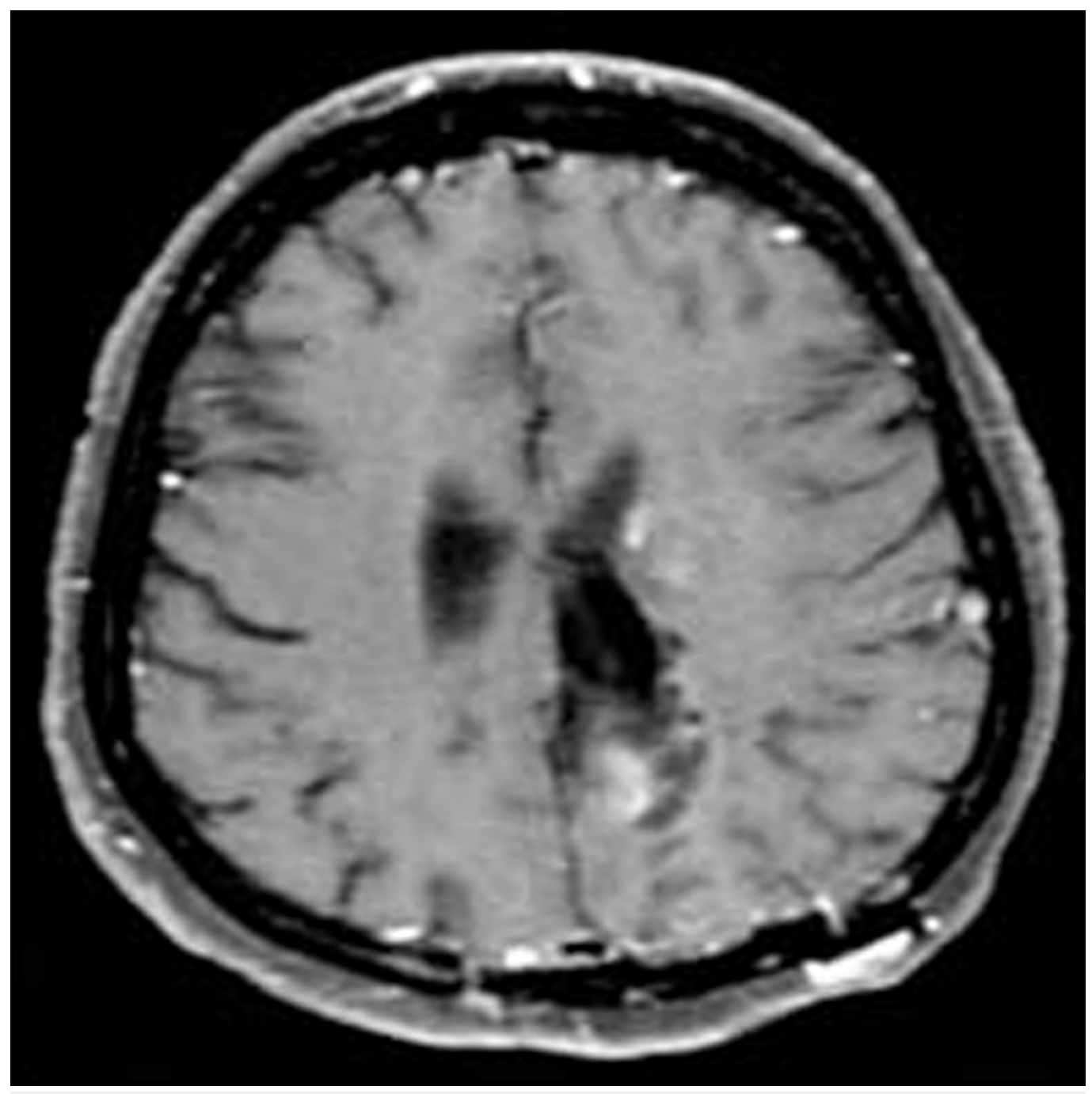

FIGURE 7:

MR imaging and histology related to the third resection. Preoperative T1-weighted MRI with contrast. 


\section{Cureus}

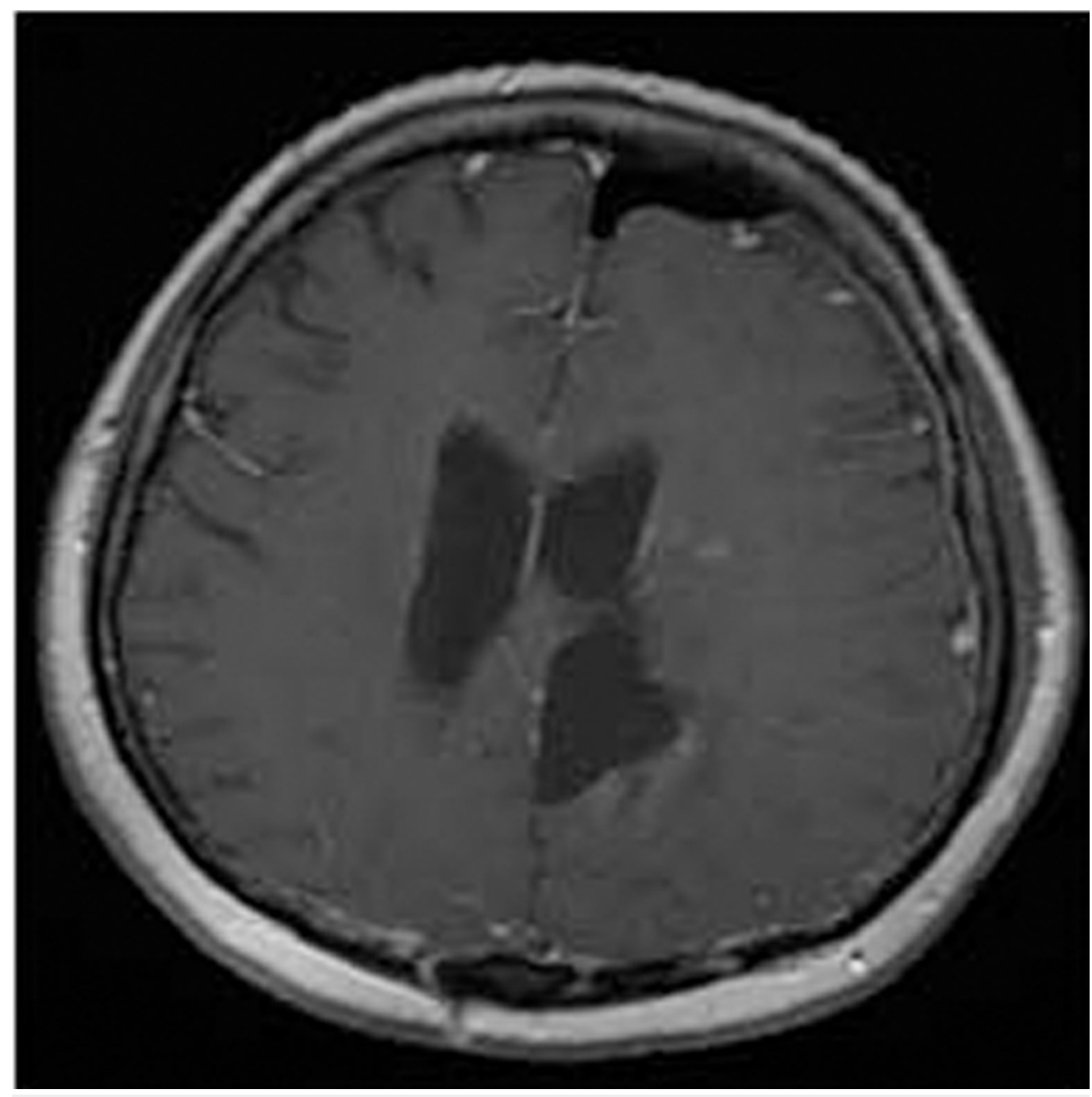

\section{FIGURE 8:}

MR imaging and histology related to the third resection. Postoperative T1-weighted MRI with contrast revealed a gross total resection of the lesion.

Pathology from the third resection revealed fibrillary astrocytoma without notable gemistocytic component (Figure 9). 


\section{Cureus}

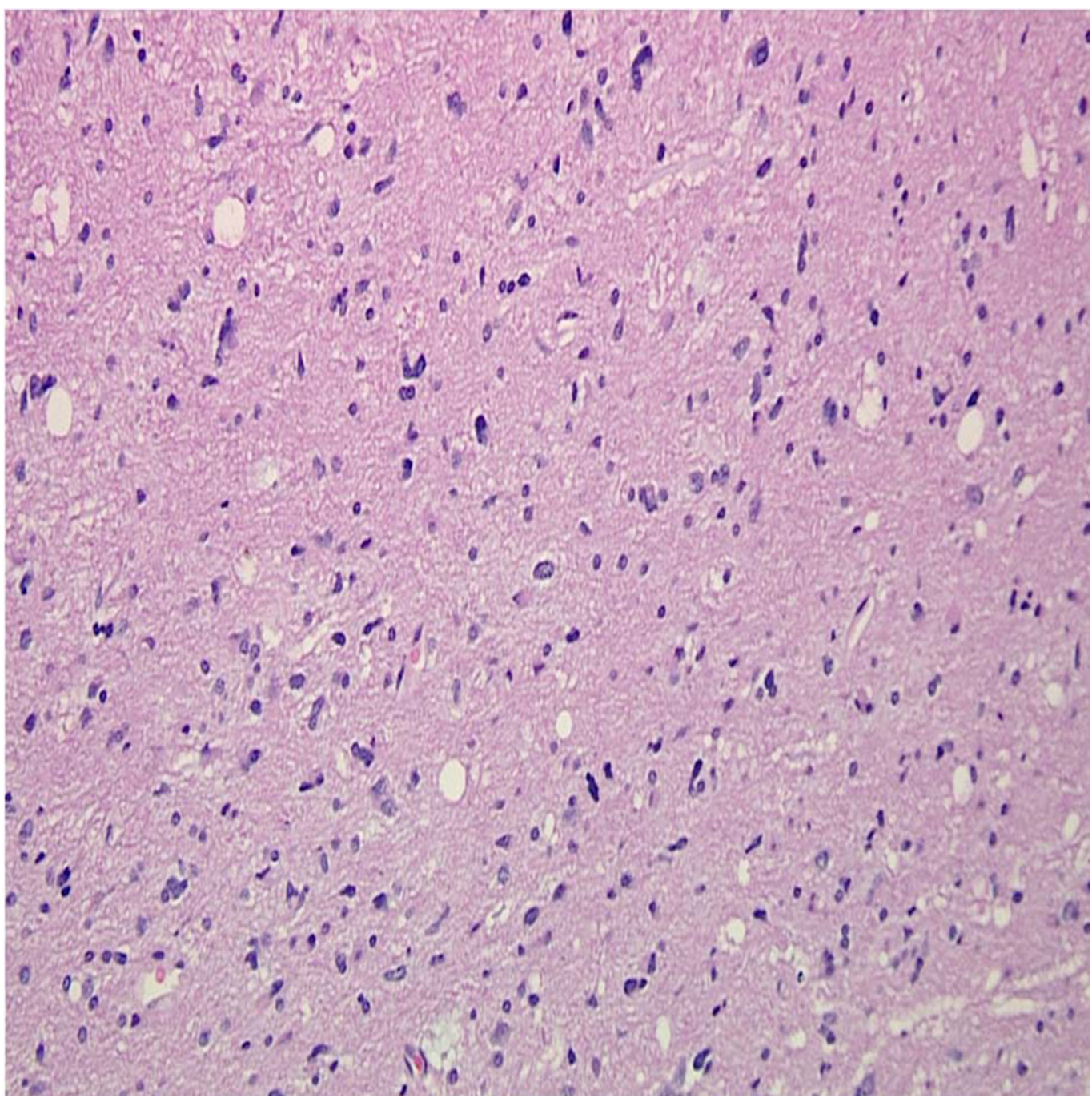

FIGURE 9:

Representative pathology from the resected specimen. Specimen revealed a fibrillary astrocytoma with modest cellularity (hematoxylin-eosin, original magnification $x 400$ ).

All resection specimens were IDH1 mutated and positive for MGMT promoter methylation. Six weeks after the third craniotomy, the patient was initiated on a regimen of Avastin/CPT-11.

\section{Discussion}

To our knowledge, this is the first documented case of an astrocytoma that converted from a more aggressive gemistocytic form to a less aggressive fibrillary form. The case is unusual in that a gemistocytic astrocytoma nearly always progresses to less differentiated/anaplastic histology. This is the first case where this typical progression pattern was not observed in over thirty years of clinical practice by the senior pathologist of this case report.

We speculate that the phenomenon is the result of the inherently heterogeneous astrocytoma subpopulations. Over the past two decades, conceptualization of astrocytomas has evolved from a collection of relatively homogenous cells to the recognition of distinct sub-populations of tumor cells to that of a complex organ, with constant interactions between tumor cells [3-4]. Pre-clinical data suggest that these differing sub-populations of cells exhibit distinct response to chemotherapy and radiation therapy [5-6]. These results suggest that the predominant 
tumor histology may be altered by selective pressures imposed by therapy. In our case report, if the predominant gemistocytic sub-population of tumor cells is more sensitive to chemo/radiation therapy than a rarer fibrillary subpopulation, the rarer subpopulation may have an opportunity to expand to become the predominant sub-population after therapeutic intervention [7-8].

It is important to note other explanations of the phenomenon reported here. For instance, recent studies suggest that malignant gliomas harbor subpopulations of "stem" like cells capable of differentiating into distinct cell fates [3, 9]. Moreover, the process of dedifferentiation and differentiation appear highly dynamic [9-11]. In this context, it is conceivable that the selective pressure imposed by the therapy led to either differentiation or de-differentiation processes that resulted in a change in overall histology.

The major limitation of this case report is that we cannot exclude the possibility that the change in pathology was entirely due to sampling error. The tumor described could have always been a mixed gemistocytic/fibrillary astrocytoma with geographically distinct subpopulations. In this scenario, these distinct geographic regions were sampled during the three different craniotomies. We believe that this scenario is unlikely for the following reasons: First, multiple and generous specimens were secured in all three craniotomies. Further, all specimens were carefully scrutinized by a team of experienced neuropathologists for the purpose of this case report. While sampling errors in specimen analysis is a known phenomenon, these errors are typically associated with small and limited specimens secured through stereotactic biopsies rather than generous samples secured through craniotomies [1214]. Second, analysis of the pre- and postoperative MRIs, as well as the operative notes, revealed that the specimens were secured from a wide distribution of geographic local within the tumor region.

\section{Conclusions}

The importance of this case report is that it illustrates the dynamic nature of the astrocytoma sub-populations and emphasizes tumor heterogeneity as a concept in terms of therapeutic development. Ultimately, rational therapeutic agents targeting distinct sub-populations of glioblastoma cells will be required before meaningful clinical impact can be achieved.

\section{Additional Information}

\section{Disclosures}

Human subjects: Consent was obtained by all participants in this study. Conflicts of interest: In compliance with the ICMJE uniform disclosure form, all authors declare the following: Payment/services info: All authors have declared that no financial support was received from any organization for the submitted work. Financial relationships: All authors have declared that they have no financial relationships at present or within the previous three years with any organizations that might have an interest in the submitted work. Other relationships: All authors have declared that there are no other relationships or activities that could appear to have influenced the submitted work.

\section{References}

1. Louis DN, Ohgaki H, Wiestler OD, Cavenee WK, Burger PC, Jouvet A, Scheithauer BW, Kleihues P: The 2007 WHO classification of tumours of the central nervous system. Acta Neuropathol. 2007, 114:97-109.

2. Visvader JE, Lindeman GJ: Cancer stem cells: Current status and evolving complexities . Cell Stem Cell. 2012, 10:717-28. 10.1016/j.stem.2012.05.007

3. Bartek J Jr., Ng K, Bartek J, Fischer W, Carter B, Chen CC: Key concepts in glioblastoma 
therapy. J Neurol Neurosurg Psychiatry. 2012, 83:753-60. 10.1136/jnnp-2011-300709

4. Hanahan D, Weinberg RA: Hallmarks of cancer: The next generation . Cell. 2011, 144:646-74. 10.1016/j.cell.2011.02.013

5. Bao S, Wu Q, McLendon RE, Hao Y, Shi Q, Hjelmeland AB, Dewhirst MW, Bigner DD, Rich JN: Glioma stem cells promote radioresistance by preferential activation of the DNA damage response. Nature. 2006, 444:756-60.

6. Inda MM, Bonavia R, Mukasa A, Narita Y, Sah DW, Vandenberg S, Brennan C, Johns TG, Bachoo R, Hadwiger P, Tan P, Depinho RA, Cavenee W, Furnari F: Tumor heterogeneity is an active process maintained by a mutant EGFR-induced cytokine circuit in glioblastoma. Genes Dev. 2010, 24:1731-45. 10.1101/gad.1890510

7. Giaccone G: EGFR point mutation confers resistance to gefitinib in a patient with non-smallcell lung cancer. Nat Clin Pract Oncol. 2005, 2:296-7.

8. Kobayashi S, Boggon TJ, Dayaram T, Jänne PA, Kocher O, Meyerson M, Johnson BE, Eck MJ, Tenen DG, Halmos B: EGFR mutation and resistance of non-small-cell lung cancer to gefitinib. N Engl J Med. 2005, 352:786-92.

9. Nguyen LV, Vanner R, Dirks P, Eaves CJ: Cancer stem cells: An evolving concept . Nat Rev Cancer. 2012, 12:133-43. 10.1038/nrc3184

10. Kuchina A, Espinar L, Garcia-Ojalvo J, Süel GM: Reversible and noisy progression towards a commitment point enables adaptable and reliable cellular decision-making. PLoS Comput Biol. 2011, 7:e1002273. 10.1371/journal.pcbi.1002273

11. Glantz MJ, Burger PC, Herndon JE 2nd, Friedman AH, Cairncross JG, Vick NA, Schold SC Jr: Influence of the type of surgery on the histologic diagnosis in patients with anaplastic gliomas. Neurology. 1991, 41:1741-4.

12. Wen PY, Kesari S: Malignant gliomas in adults. N Engl J Med. 2008, 359:492-507. 10.1056/NEJMra0708126

13. Jackson RJ, Fuller GN, Abi-Said D, Lang FF, Gokaslan ZL, Shi WM, Wildrick DM, Sawaya R: Limitations of stereotactic biopsy in the initial management of gliomas . Neuro Oncol. 2001, 3:193-200.

14. Perry A, Jenkins RB, O'Fallon JR, Schaefer PL, Kimmel DW, Mahoney MR, Scheithauer BW, Smith SM, Hill EM, Sebo TJ, Levitt R, Krook J, Tschetter LK, Morton RF, Buckner JC: Clinicopathologic study of 85 similarly treated patients with anaplastic astrocytic tumors. An analysis of DNA content (ploidy), cellular proliferation, and p53 expression. Cancer. 1999, 86:672-83. 